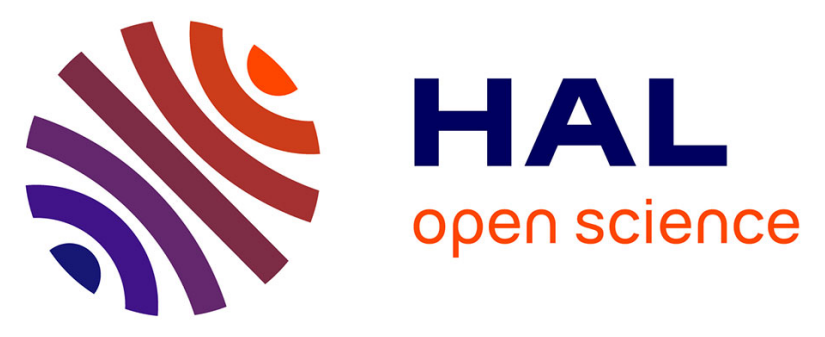

\title{
Carbon monoxide pollution promotes cardiac remodeling and ventricular arrhythmia in healthy rats.
}

Lucas Andre, Julien Boissière, Cyril Reboul, Romain Perrier, Santiago

Zalvidea, Gregory Meyer, Jérome Thireau, Stéphane Tanguy, Patrice Bideaux, Maurice Hayot, et al.

\section{To cite this version:}

Lucas Andre, Julien Boissière, Cyril Reboul, Romain Perrier, Santiago Zalvidea, et al.. Carbon monoxide pollution promotes cardiac remodeling and ventricular arrhythmia in healthy rats.. American Journal of Respiratory and Critical Care Medicine, 2010, 181 (6), pp.587-95. 10.1164/rccm.2009050794OC . hal-00688245

\section{HAL Id: hal-00688245 \\ https://hal.science/hal-00688245}

Submitted on 17 Apr 2012

HAL is a multi-disciplinary open access archive for the deposit and dissemination of scientific research documents, whether they are published or not. The documents may come from teaching and research institutions in France or abroad, or from public or private research centers.
L'archive ouverte pluridisciplinaire HAL, est destinée au dépôt et à la diffusion de documents scientifiques de niveau recherche, publiés ou non, émanant des établissements d'enseignement et de recherche français ou étrangers, des laboratoires publics ou privés. 


\title{
Carbon Monoxide Pollution Promotes Cardiac Remodeling and Ventricular Arrhythmia in Healthy Rats
}

\author{
Lucas Andre ${ }^{*}$, Julien Boissière ${ }^{1,2 *}$, Cyril Reboul ${ }^{2}$, Romain Perrier ${ }^{1}$, Santiago Zalvidea ${ }^{1}$, Gregory Meyer ${ }^{2}$, \\ Jérôme Thireau', Stéphane Tanguy'2, Patrice Bideaux', Maurice Hayot ${ }^{3}$, François Boucher ${ }^{4}$, Philippe Obert², \\ Olivier Cazorla ${ }^{1}$, and Sylvain Richard ${ }^{1}$
}

${ }^{1}$ INSERM, U-637 and ${ }^{3}$ INSERM ERI25, Université Montpellier1, Université Montpellier2, Montpellier; ${ }^{2}$ EA-4278, Université Avignon et des Pays de Vaucluse, UFR Sciences, Avignon; and ${ }^{4}$ UMR5525, Laboratoire TIMC-PRETA, Université de Grenoble, La Tronche, France

Rationale: Epidemiologic studies associate atmospheric carbon monoxide (CO) pollution with adverse cardiovascular outcomes and increased cardiac mortality risk. However, there is a lack of data regarding cellular mechanisms in healthy individuals.

Objectives: To investigate the chronic effects of environmentally relevant $\mathrm{CO}$ levels on cardiac function in a well-standardized healthy animal model.

Methods : Wistar rats were exposed for 4 weeks to filtered air $(\mathrm{CO}<$ $1 \mathrm{ppm}$ ) or air enriched with CO (30 ppm with five peaks of $100 \mathrm{ppm}$ per 24-h period), consistent with urban pollution. Myocardial function was assessed by echocardiography and analysis of surface ECG and in vitro by measuring the excitation-contraction coupling of single left ventricular cardiomyocytes.

Measurements and Main Results: Chronic CO pollution promoted left ventricular interstitial and perivascular fibrosis, with no change in cardiomyocyte size, and had weak, yet significant, effects on in vivo cardiac function. However, both contraction and relaxation of single cardiomyocytes were markedly altered. Several changes occurred, including decreased $\mathrm{Ca}^{2+}$ transient amplitude and $\mathrm{Ca}^{2+}$ sensitivity of myofilaments and increased diastolic intracellular $\mathrm{Ca}^{2+}$ subsequent to decreased SERCA-2a expression and impaired $\mathrm{Ca}^{2+}$ reuptake. $\mathrm{CO}$ pollution increased the number of arrhythmic events. Hyperphosphorylation of $\mathrm{Ca}^{2+}$-handling and sarcomeric proteins, and reduced responses to $\beta$-adrenergic challenge were obtained, suggestive of moderate $\mathrm{CO}$-induced hyperadrenergic state.

Conclusions: Chronic CO exposure promotes a pathological phenotype of cardiomyocytes in the absence of underlying cardiomyopathy. The less severe phenotype in vivo suggests a role for compensatory mechanisms. Arrhythmia propensity may derive from intracellular $\mathrm{Ca}^{2+}$ overload.

Keywords: heart failure; atmospheric pollution; $\mathrm{Ca}^{2+}$ handling; protein kinase A pathway

The World Health Organization estimates that 3 million people are killed annually worldwide by outdoor air pollution caused by vehicles and industrial emissions (http://www.who.int; http:// www.infoforhealth.org). Notably, air pollution increases the risk of mortality from cardiovascular disease by $76 \%$ (1) with deaths related to ischemia, ventricular arrhythmia (VA), and heart

(Received in original form May 27, 2009; accepted in final form December 16, 2009) Supported by a French National Research Agency grant (COMYOCARD).

* These authors contributed equally to this work.

Correspondence and requests for reprints should be addressed to Sylvain Richard, Ph.D., INSERM U-637 Physiopathologie Cardiovasculaire, CHU Arnaud de Villeneuve, F-34295 Montpellier, France. E-mail: sylvain.richard@inserm.fr

This article has an online supplement, which is accessible from this issue's table of contents at www.atsjournals.org

Am J Respir Crit Care Med Vol 181. pp 587-595, 2010

Originally Published in Press as DOI: 10.1164/rccm.200905-07940C on December 17, 2009 Internet address: www.atsjournals.org

\section{AT A GLANCE COMMENTARY}

\section{Scientific Knowledge on the Subject}

Most studies of the effects of atmospheric pollution provide correlations between air quality and cardiovascular outcomes, but do not provide mechanistic information owing to technical limitations in human subjects. Our findings provide a rationale at the cellular and molecular levels in support of epidemiologic studies pointing to the deleterious effects of carbon monoxide pollution on cardiac function.

\section{What This Study Adds to the Field}

This study shows that the deleterious effects of chronic carbon monoxide exposure may be barely detectable. However, even in the absence of underlying cardiopathy, cardiomyocytes may develop a pathological phenotype with some features commonly observed at the early stages of heart failure.

failure (HF) (2-4). Among the various agents that constitute the mix of atmospheric pollution, carbon monoxide $(\mathrm{CO})$ is a ubiquitous pollutant found in many common sources (secondhand smoke, vehicular exhaust, industrial emissions, etc.). Outdoor $\mathrm{CO}$ exposure is closely associated with hospital admissions for cardiovascular disease (5) as well as cardiac mortality (6). In addition, $\mathrm{CO}$ pollution increases HF risk factors, such as blood viscosity and arrhythmia (7), and decreases heart rate variability $(8,9)$. However, studies investigating the effects of urban air pollution in humans are mainly restricted to epidemiological studies that only establish correlations between air quality and cardiovascular outcome. In this context, it is particularly difficult to discriminate the pathophysiological effects of various major atmospheric pollutants, such as $\mathrm{CO}$, particulate matter, or lead. In addition, the mechanisms underlying the effects of chronic $\mathrm{CO}$ exposure on the heart have not been well established. In this regard, the use of an animal model has several advantages, including better standardization of experimental approaches and insights into cellular mechanisms.

The aim of our work was to investigate the effects of chronic $\mathrm{CO}$ exposure, under conditions mimicking urban air pollution, on rat cardiac function both in vivo and at the cardiomyocyte level. Our principal results were that chronic $\mathrm{CO}$ pollution initiated a pathological phenotype characterized by serious remodeling of the excitation-contraction coupling (ECC) of cardiomyocytes, with major alterations of $\mathrm{Ca}^{2+}$ handling leading to increased risk of VA. 


\section{METHODS}

For a detailed description, see METHODs in the online data supplement. Experiments were performed with approval of the institutional animal care and use committee.

\section{Animal Model and Chronic CO Exposure}

In urban areas, ambient $\mathrm{CO}$ usually varies between 2 and $40 \mathrm{ppm}$, but under certain circumstances, such as during heavy traffic, its concentration may reach levels as high as $150-200$ ppm $(10,11)$. In our study, male Wistar rats $(13 \mathrm{wk}$ old, $\mathrm{n}=35)$ were exposed to $\mathrm{CO}$ in an airtight exposure container over 4 weeks. Rats were exposed to a basal $\mathrm{CO}$ concentration of $30 \mathrm{ppm}$ during a 12-hour period completed with five peaks of $100 \mathrm{ppm}(1 \mathrm{~h}$ each), to reproduce environmentally relevant variations in air quality (schema included in supplemental data). For the remaining 12 hours, the $\mathrm{CO}$-exposed group of rats was exposed to filtered air $(<1 \mathrm{ppm} \mathrm{CO})$. The $\mathrm{CO}$ content was continuously monitored with an infrared aspirative $\mathrm{CO}$ analyzer (CHEMGARD, NEMA 4 Version, MSA, Greer, SC). Rats exposed to CO pollution were compared with rats exposed to filtered ambient air $(\mathrm{CO}<1 \mathrm{ppm}$; control, $\mathrm{n}=25)$. Experiments were performed $24 \mathrm{~h}$ after the last $\mathrm{CO}$ exposure to avoid acute $\mathrm{CO}$ effects. Carboxyhemoglobin level measured 24 hours after the last $\mathrm{CO}$ exposure $(1.2 \pm 0.4 \%)$ did not differ from that of the control group $(1.02 \pm 0.22 \%)$ and was consistent with levels reached in human population exposed to high atmospheric pollution $(12,13)$.

\section{In vivo Cardiac Investigation}

Doppler echocardiography was performed to evaluate cardiac function and morphology (14). Hemodynamic evaluation (arterial and ventricular pressures) was performed in intact closed-chest anesthetized rats 24 hours after echocardiography (14). Measurements were performed before and after a $\beta$-adrenergic challenge by isoproterenol perfusion $(1 \mathrm{mg} / \mathrm{kg} / \mathrm{min}$ ). Surface ECG recordings (Dataquest; Data Sciences International, Transoma Medical, Arden Hills, MN) were performed for a 24-hour period after the CO exposure protocol. Spontaneous rhythmic disorders, heart rate variability, mean, and standard deviation of all normal RR intervals were calculated from ECGs $(24 \mathrm{~h})$.

\section{Histology}

The quantification of interstitial fibrillar collagen content was performed on Sirius red-stained sections using morphometry (Lucia digital image analysis software; Nikon, Melville, NY).

\section{Cardiac ECC Analysis}

$\mathrm{Ca}^{2+}$ transient and cell fractional shortening. Single ventricular myocytes were isolated by enzymatic digestion as previously described (15). Unloaded cell shortening and $\mathrm{Ca}^{2+}$ concentration (Indo-1 dye) were measured using field stimulation $\left(0.5 \mathrm{~Hz}, 22^{\circ} \mathrm{C}, 1.8 \mathrm{mM}\right.$ external $\left.\mathrm{Ca}^{2+}\right)$. Sarcomere length (SL) and fluorescence ( 405 and $480 \mathrm{~nm}$ ) were simultaneously recorded (IonOptix system, Milton, MA) under basal conditions and after $\beta$-adrenergic stimulation with isoproterenol $(100 \mathrm{nM})$.

Action potentials, L-type $\mathrm{Ca}^{2+}$ current, and $\mathrm{K}^{+}$currents. Whole-cell patch-clamp experiments were performed $\left(22 \pm 2^{\circ} \mathrm{C}\right)$ with an Axopatch 200B (Axon Instruments, Burlingham, CA) (16). Currents were normalized to cell membrane capacitance $(\mathrm{Cm})$ and expressed as densities. Because of the heterogeneity in action potential (AP) duration across the left ventricular (LV) free wall (17), we separated subepicardial and subendocardial cells.

Force measurements in permeabilized cardiomyocytes. Isometric force was measured in single permeabilized cardiomyocytes (18). Force was normalized to the cross-sectional area measured by imaging (IonOptix system). The relationship between $\mathrm{Ca}^{2+}$ activated force and internal $\mathrm{Ca}^{2+}$ concentration was measured at $2.3 \mu \mathrm{m} \mathrm{SL}$ and was fitted with a modified Hill equation. In some experiments, permeabilized cardiomyocytes were incubated with a recombinant catalytic subunit of protein kinase A (PKA, Sigma, St. Quentin, France) for $50 \mathrm{~min}$ at room temperature (19).

\section{Protein Analysis}

$\mathrm{Ca}^{2+}$ handling. Proteins were separated using 2 to $20 \%$ sodium dodecyl sulfate-polyacrylamide gel electrophoresis. Proteins were revealed with specific antibodies and were expressed relative to calsequestrin content.

Myofilament proteins. Myofibrillar proteins were analyzed on skinned muscle strips from the LV (18). Phosphorylated and nonphosphorylated MLC-2 forms were detected with a cardiac MLC-2specific antibody (Coger SA, Paris, France). TnI was revealed using specific antibodies for total cardiac TnI (Cat\#4T21; Hytest, Turku, Finland) or the PKA-phosphorylated form of cardiac TnI (Cat\#4T45; Hytest).

\section{Cardiac Oxidative Status}

Hearts ( $n=6$ per group) were freeze-clamped and the frozen ventricular tissue was homogenized in TRIS HCl buffer (TRIS HCl $60 \mathrm{mM}$, diethyltriaminopentaacetic acid $1 \mathrm{mM}, \mathrm{pH} 7.4,10 \mathrm{ml} / \mathrm{g}$ wet wt.), using a Teflon Potter homogenizer. Tissue homogenates were then centrifuged (10 min at $20,000 \times g$ at $4^{\circ} \mathrm{C}$ ). Activities of total superoxide dismutase, catalase, and glutathione peroxidase, reflecting the antioxidant status, and thioredoxin reductase, reflecting the oxidant status, were measured in supernatants $(20)$

\section{Statistical Analysis}

Statistics were performed using StatView 5.0 (SAS Institute, Cary, NC). Data are presented as mean \pm SEM unless otherwise specified. The effects of $\mathrm{CO}$ exposure, time, and/or $\beta$-adrenergic challenge were analyzed using one-way factorial analysis of variance or analysis of variance with repeated measures depending on the variables studied. Bonferroni post hoc tests were realized where appropriate. Statistical significance was defined as $P$ less than 0.05 .

\section{RESULTS}

\section{Effects of CO Exposure on In Vivo Cardiac Morphology and Function}

Chronic exposure to $\mathrm{CO}$ altered heart morphology and function. Rats from the $\mathrm{CO}$ group exhibited hypertrophic features, with increased heart weight/body weight as well as LV/body weight ratios. LV interstitial and perivascular fibrous tissue was

\section{TABLE 1. EFFECTS OF CHRONIC CARBON MONOXIDE EXPOSURE ON CARDIOVASCULAR FUNCTION AND CARDIAC MORPHOLOGY IN VIVO}

\begin{tabular}{lcc}
\hline & $\begin{array}{c}\text { Control } \\
(n=12)\end{array}$ & $\begin{array}{c}\text { CO } \\
(n=16)\end{array}$ \\
\hline $\begin{array}{l}\text { Morphological data } \\
\text { Body wt, g }\end{array}$ & \\
Heart wt/100 g body wt, mg/100 g & $259 \pm 9$ & $511 \pm 5$ \\
LV/100 g body wt, mg/100 g & $204 \pm 5$ & $276 \pm 6^{*}$ \\
$\quad$ Fibrosis, \% of total area & $1.96 \pm 0.29$ & $219 \pm 4^{*}$ \\
Echocardiographic data & & $3.72 \pm 0.4^{*}$ \\
LVEdD, mm & $9.46 \pm 0.14$ & $9.61 \pm 0.21$ \\
LVEsD, mm & $5.76 \pm 0.17$ & $6.30 \pm 0.16^{*}$ \\
Anterior wall thickness, mm & $1.02 \pm 0.04$ & $1.06 \pm 0.06$ \\
Posterior wall thickness, mm & $1.16 \pm 0.11$ & $1.29 \pm 0.19^{*}$ \\
LV shortening fraction, \% & $39.22 \pm 1.18$ & $34.35 \pm 1.11^{*}$ \\
Posterior wall end-systolic strain, \% & $98 \pm 7$ & $78 \pm 9^{*}$ \\
E/A-wave velocity ratio & $1.89 \pm 0.33$ & $1.98 \pm 0.34$ \\
Hemodynamic data & & \\
$\quad$ Systolic arterial pressure, mm Hg & $120 \pm 10$ & $121 \pm 4$ \\
Diastolic arterial pressure, mm Hg & $93 \pm 9$ & $96 \pm 4$ \\
Mean arterial pressure, mm Hg & $102 \pm 10$ & $105 \pm 5$ \\
LV developed pressure, mm Hg & $104 \pm 5$ & $106 \pm 5$ \\
LV dP/dt max, mm Hg/s & $5018 \pm 326$ & $4781 \pm 255$ \\
LV dP/dt min, mm Hg/s & $-4700 \pm 285$ & $-4676 \pm 287$ \\
LV tau, s & $8.22 \pm 0.27$ & $8.31 \pm 0.16$
\end{tabular}

Definition of abbreviations: $\mathrm{CO}=$ carbon monoxide; $\mathrm{LV}=$ left ventricular; LVEdD = left ventricular end-diastolic diameter; LVEsD = left ventricular endsystolic diameter; $\mathrm{LV} \mathrm{dP} / \mathrm{dt} \max =$ maximal first derivative of left ventricular pressure; $\mathrm{LV} \mathrm{dP/dt} \mathrm{min} \mathrm{=} \mathrm{minimal} \mathrm{first} \mathrm{derivative} \mathrm{of} \mathrm{left} \mathrm{ventricular} \mathrm{pressure;} \mathrm{LV}$ tau $=$ time constant of left ventricular pressure decay; ${ }^{*} P<0.05$ vs. control. 


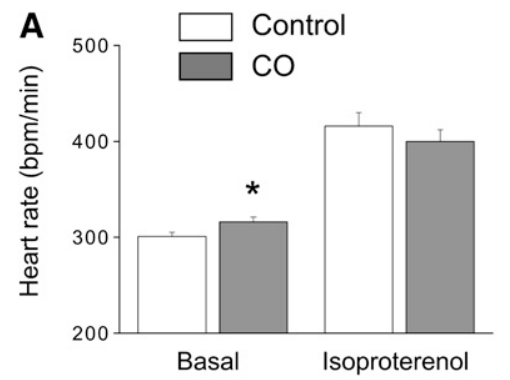

B VT

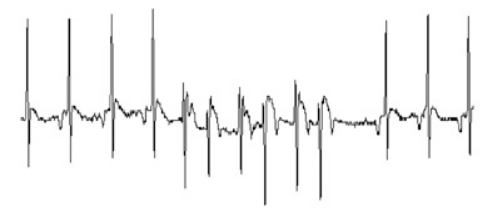

VEB

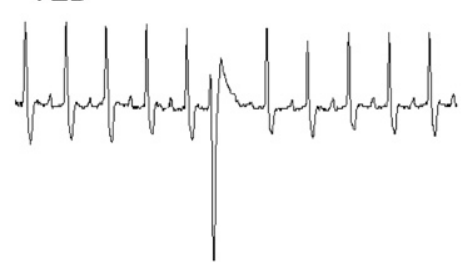

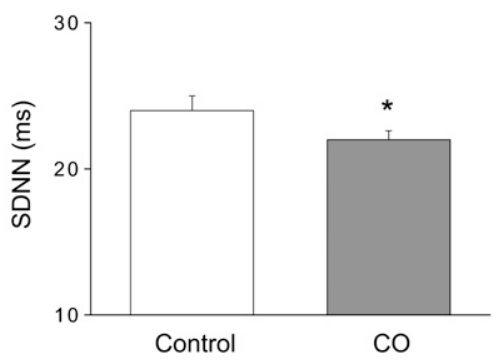

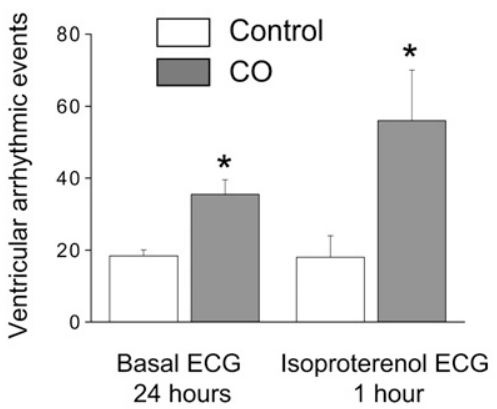

Figure 1. Analysis of in vivo arrhythmic events from ECG recordings and heart rate variability analysis in control and carbon monoxide (CO)-exposed rats. $(A)$ Heart rate under basal conditions and after injection of isoproterenol $(1 \mathrm{mg} / \mathrm{kg}$ i.p.) (right) and standard deviation of the normal RR intervals (left ) ( $\mathrm{n}=9$ rats in each group). (B) Typical examples of arrhythmic events occurring during 24-hour ECG recordings (left ); analysis of the occurrence of arrhythmic events during 24-h measurements and after acute challenge with isoproterenol (average number of arrhythmic events over $1 \mathrm{~h}$ postinjection) (right). ${ }^{*} P<0.05$. VEB $=$ ventricular ectopic beat; $\mathrm{VT}=$ ventricular tachycardia nearly doubled (Table 1; see Figure E2 in the online supplement). An increase in posterior wall thickness was observed, associated with a slight but significant global contractile dysfunction as indicated by a decrease in the LV shortening fraction and posterior wall end-systolic strain (Table 1). However, arterial blood pressure and LV hemodynamic parameters were similar in CO-exposed and control rats (Table 1). Taken together, our data suggested that chronic $\mathrm{CO}$ exposure has a weak, yet significant, effect on in vivo cardiac function.

\section{Electrical Activity of Heart Measured In Vivo and Heart Rate Variability}

Surface ECGs were recorded and analyzed in conscious rats from control and $\mathrm{CO}$ groups. Chronic $\mathrm{CO}$ exposure increased basal heart rate (Figure 1A) from $297 \pm 2 \mathrm{bpm}$ in control rats $(\mathrm{n}=8)$ to $320 \pm 8 \mathrm{bpm}$ in CO-exposed rats $(\mathrm{n}=9 ; P<0.02)$, whereas the QTc interval remained unchanged $(44.1 \pm 0.8 \mathrm{~ms}$ vs. $43.1 \pm 0.5 \mathrm{~ms}$, respectively). The PR intervals were also unchanged between control and CO-exposed rats $(45.0 \pm 0.5$ and $44.0 \pm 0.7 \mathrm{~ms}$, respectively). After the animals were challenged with the $\beta$-adrenergic receptor agonist isoproterenol ( $1 \mathrm{mg} / \mathrm{kg}$ i.p.), the difference in heart rate between the two groups was abolished, reflecting a weaker response to $\beta$-adrenergic stimulation in CO-exposed rats (Figure 1A). The standard deviation of normal-to-normal intervals, an estimate of overall heart rate variability, was decreased in CO-exposed rats (Figure 1A). The number of premature ventricular beats doubled in this group (Figure 1B). The occurrence of nonsustained tachycardia, which is absent in controls, was detected in CO-exposed rats. The number of atrioventricular blocks was unchanged between control and CO-exposed rats (5.2 \pm 1.2 and $6.3 \pm 1.5$ atrioventricular blocks $/ 24 \mathrm{~h}$, respectively). After the animals were
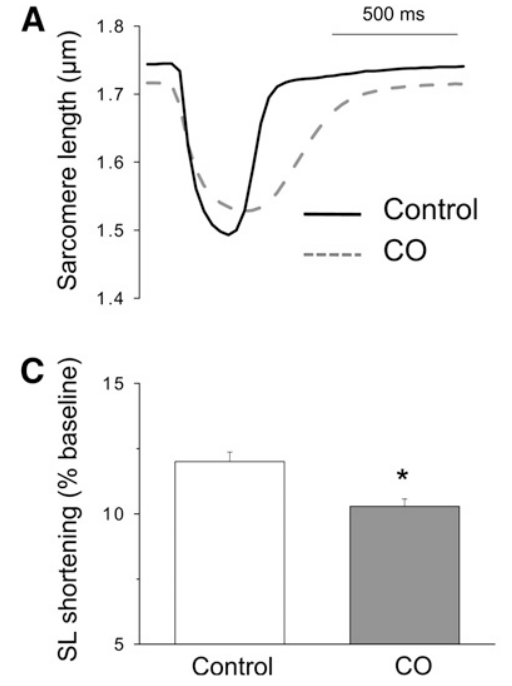
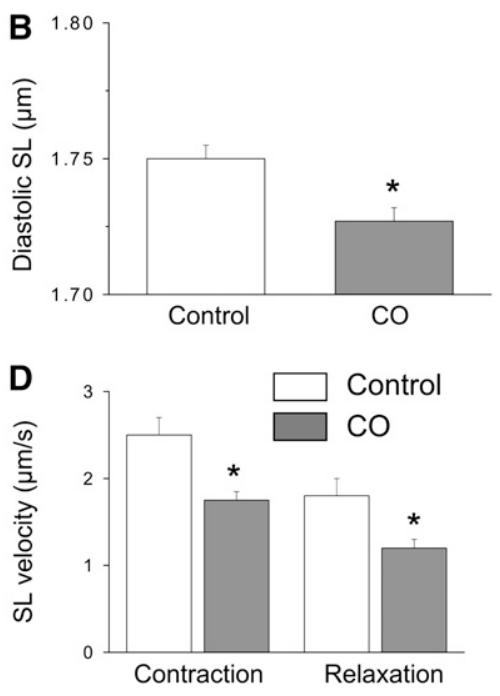

Figure 2. Chronic exposure to carbon monoxide (CO) pollution alters cardiomyocyte contraction. $(A)$ Contraction of intact myocytes, measured by sarcomere length (SL) shortening at $0.5 \mathrm{~Hz}$, isolated from rats exposed to $\mathrm{CO}$ pollution ( $\mathrm{CO}$, dashed line) and from control rats (solid line). (B) Diastolic SL, (C) the amplitude of SL shortening, and (D) velocities of contraction and relaxation were decreased after chronic $\mathrm{CO}$ exposure. Results represent the mean \pm SEM of cells from five hearts $(n=112-145) .{ }^{*} P<0.05$. 
A Control

$\mathrm{CO}$
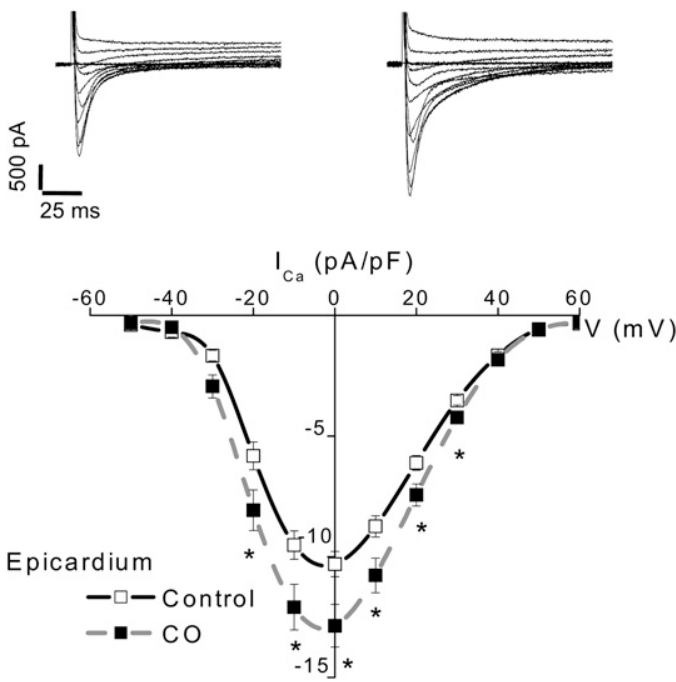

C
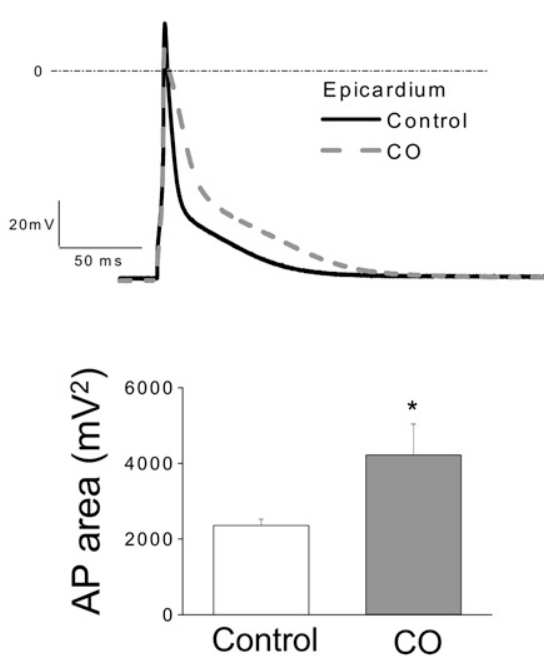

B Control $\mathrm{CO}$
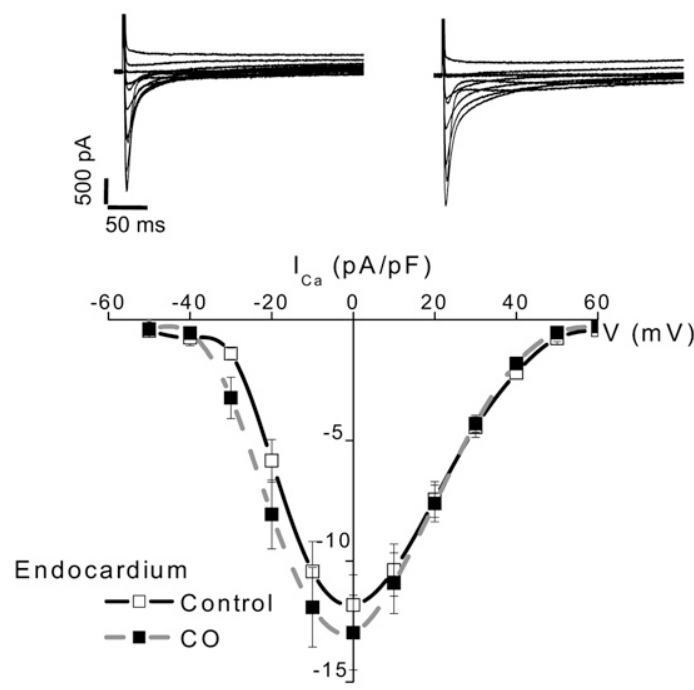

D
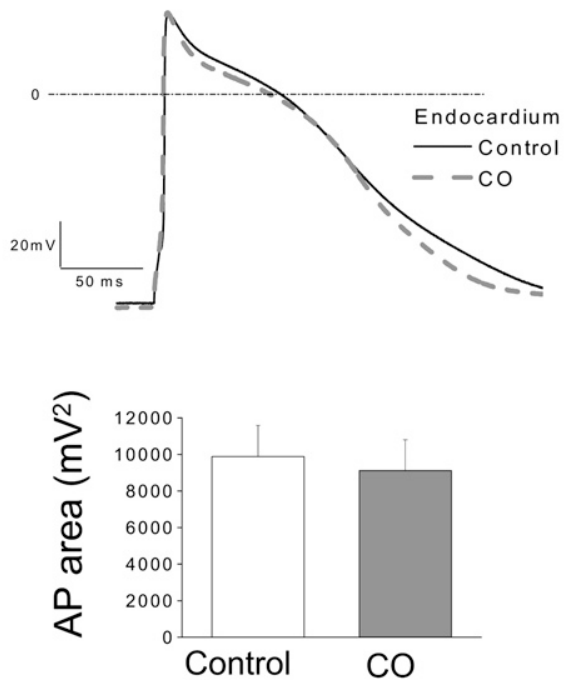

Figure 3. Chronic carbon monoxide (CO) pollution modifies the action potential (AP) in ventricular myocytes. Typical L-type inward calcium current $\left(\mathrm{I}_{\mathrm{Ca}, \mathrm{L}}\right)$ evoked by depolarizations between $-50 \mathrm{mV}$ and $+60 \mathrm{mV}$ at $10-\mathrm{mV}$ increments, from a holding potential of -80 $\mathrm{mV}$, in control and $\mathrm{CO}$ cardiomyocytes from $(A)$ the epicardial area and $(B)$ the endocardial area, with the corresponding average current-tovoltage relationships of $\mathrm{I}_{\mathrm{Ca}, \mathrm{L}}$. $(C, D)$ Superimposed APs recorded at $0.1 \mathrm{~Hz}$, and corresponding averaged AP area in control and CO cardiomyocytes from $(C)$ the epicardial area and $(D)$ the endocardial area. For all groups $(n=8-14$ cells $/ 5$ hearts), ${ }^{*} p<0.05$. challenged with isoproterenol, the number of premature ventricular beats (measured during the $2 \mathrm{~h}$ after isoproterenol perfusion) increased in the two groups. However, not only did the absolute risk of arrhythmic events remain greater in the $\mathrm{CO}$ exposed group, but the risk was potentiated (Figure 1B) with the promotion of ventricular ectopic beats that are potential triggers, inducing the start of a sustained arrhythmia.

\section{Effects of CO Exposure on Cardiac ECC}

At the cellular level, chronic CO exposure decreased cell fractional shortening (reflecting contraction) in intact ventricular myocytes (Figures 2A and 2C). This decrease was associated with a reduction in diastolic SL (Figure 2B) and in the maximal velocity of cell contraction and relaxation, calculated by the first derivative of cell shortening (delta SL/delta time) (Figure 1D). These results indicate that ECC is modified by chronic CO exposure.

Because of the well-known heterogeneity in AP duration across the LV free wall (17), we separated subendocardial and subepicardial cells to measure the AP and major ionic currents involved in the AP repolarizing phase. Chronic $\mathrm{CO}$ exposure had no effect on cardiomyocyte size, as estimated from measurements of cell membrane capacitance both in epicardial cells
$(\mathrm{Cm}=193 \pm 10 \mathrm{pF}, \mathrm{n}=16$ in controls vs. $203 \pm 12 \mathrm{pF}, \mathrm{n}=24$ in the $\mathrm{CO}$-exposed group) and endocardial cells $(\mathrm{Cm}=212 \pm$ $11 \mathrm{pF}, \mathrm{n}=13$ in controls vs. $204 \pm 13 \mathrm{pF}, \mathrm{n}=20$ in the COexposed group), indicating the absence of cellular hypertrophy. In epicardial cells, CO increased the density of L-type inward calcium current $\left(\mathrm{I}_{\mathrm{Ca}, \mathrm{L}}\right)$ by $20 \%$ at $0 \mathrm{mV}$, and prolonged the AP, as determined from a significant increase in AP area (Figures $3 \mathrm{~A}$ and $3 \mathrm{C}$ ). $\mathrm{CO}$ had no effect on endocardial cells. In addition, $\mathrm{CO}$ had no effect on the repolarizing outward $\mathrm{K}^{+}$current in both cell types. Thus, the regional differences in the effects of $\mathrm{CO}$ on the AP may have a limited impact on the whole-heart electrical activity.

We next investigated the effects of chronic $\mathrm{CO}$ exposure on intracellular $\mathrm{Ca}^{2+}$ in Indo-1-loaded cardiomyocytes stimulated at $0.5 \mathrm{~Hz}$. Diastolic (or basal) $\mathrm{Ca}^{2+}$ was higher and $\mathrm{Ca}^{2+}$ transient amplitude smaller in the CO-exposed group when compared with the control group (Figure 4A). The $\mathrm{Ca}^{2+}$ load of the sarcoplasmic reticulum (SR), assessed by caffeine application $(10 \mathrm{mM})$, was also reduced $(0.27 \pm 0.02$ vs. $0.34 \pm 0.02$ in CO-exposed and control rats, respectively), possibly contributing to $\mathrm{Ca}^{2+}$ transient diminution. The increase in diastolic $\mathrm{Ca}^{2+}$ could be due to a $\mathrm{Ca}^{2+}$ leak through the ryanodine receptors (RyR-2) of the SR during the diastolic phase, or to altered $\mathrm{Ca}^{2+}$ 
A
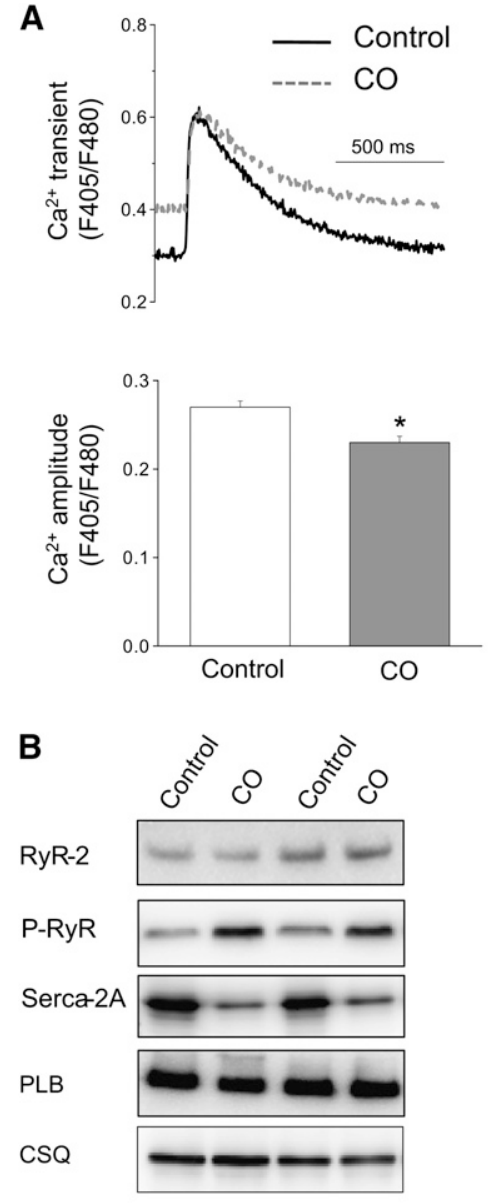
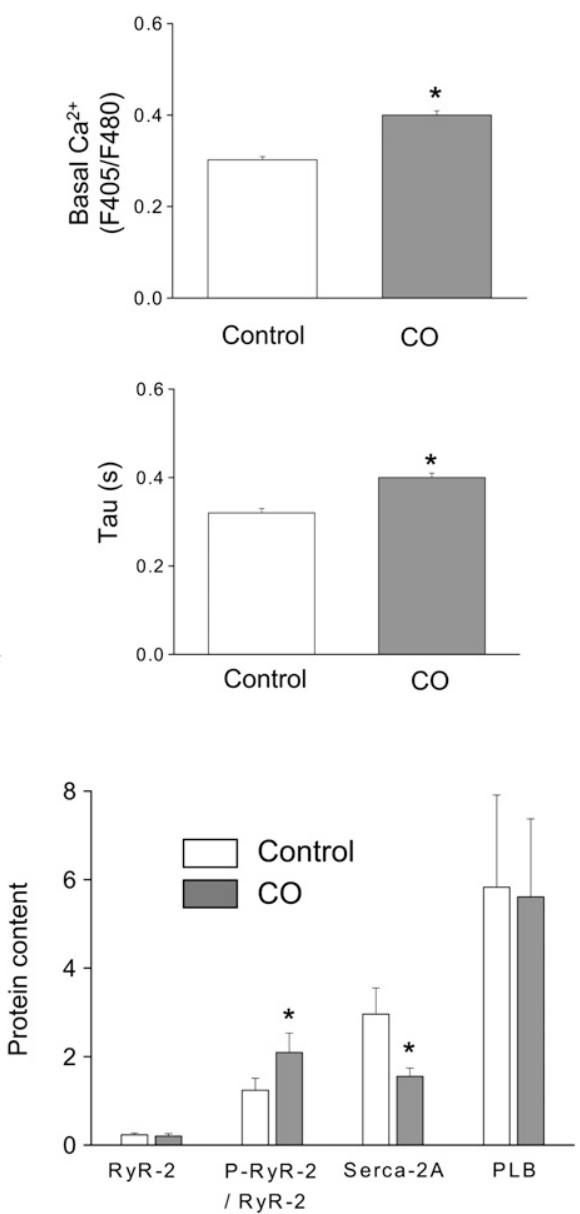

Figure 4. Chronic carbon monoxide (CO) pollution alters the $\mathrm{Ca}^{2+}$ dynamics of ventricular myocytes. $(A)$ Superimposed $\mathrm{Ca}^{2+}$ transients in intact myocytes isolated from control and CO-exposed rats. Average diastolic intracellular $\mathrm{Ca}^{2+}, \mathrm{Ca}^{2+}$ transient amplitude, and $\mathrm{Ca}^{2+}$ reuptake kinetics (tau) ( $n=112-145$ cells/5 hearts). (B) Effect of chronic exposure to $\mathrm{CO}$ on the abundance of $\mathrm{Ca}^{2+}$ handling proteins (RyR-2, PLB, and SERCA-2a), analyzed by Western blot analysis. Protein content was normalized to calsequestrin content and $\mathrm{Ser}^{2809}$ RyR-phosphorylation normalized to total RyR-2 content. Results are mean \pm SEM for five hearts. ${ }^{*} P<0.05$. reuptake by the SR (21). Chronic CO exposure had no effect on RyR-2 protein abundance (Figure 4B). However, it increased the level of RyR-2 phosphorylation on the PKA-dependent site $\mathrm{Ser}^{2809}$, which has previously been correlated with a $\mathrm{Ca}^{2+}$ leak through the RyR-2 (22). The slowing of the $\mathrm{Ca}^{2+}$ transient decay (i.e., increase in tau) in CO myocytes (Figure 4A) is consistent with an impairment of $\mathrm{Ca}^{2+}$ reuptake due either to diminished SERCA2a expression or to an inhibition of SERCA2a/PLB activity. We found that chronic CO exposure decreased SERCA-2a expression with no effect on PLB expression (Figure 4B).

Force developed by cardiomyocytes depends on both the amount of $\mathrm{Ca}^{2+}$ released by the SR and $\mathrm{Ca}^{2+}$ sensitivity of the contractile machinery. We measured the relationship between $\mathrm{Ca}^{2+}$-activated force and internal $\mathrm{Ca}^{2+}$ concentration in single permeabilized LV myocytes (Figure 5A). The cross-sectional area in permeabilized cells did not differ between the two groups $\left(203 \pm 12 \mathrm{~mm}^{2}\right.$ vs. $200 \pm 11 \mathrm{~mm}^{2}$ in control and COexposed rats, respectively), thus confirming the absence of cardiomyocyte hypertrophy revealed by cell capacitance measurements. Maximal isometric tension normalized to crosssectional area was similar in control and $\mathrm{CO}$-exposed animals. However, a rightward shift in the tension-pCa curve (i.e., decrease in myofilaments $\mathrm{Ca}^{2+}$ sensitivity, $\mathrm{pCa}_{50}$ ) in the $\mathrm{CO}$ exposed group indicated that, for a given amount of $\mathrm{Ca}^{2+}$, less force was generated by the myofilaments (Figure 5A). Myofilaments $\mathrm{Ca}^{2+}$ sensitivity is regulated by the phosphorylation status of sarcomeric proteins, such as MLC2 and cTnI (23). Chronic CO exposure did not change the phosphorylation level of MLC2 but increased the phosphorylation of cTnI at PKA sites $\left(\operatorname{Ser}^{23 / 24}\right)$ (Figure 5B). Taken together, these data demonstrate that chronic $\mathrm{CO}$ exposure alters cardiac cell contractility by modifying various stages of ECC.

\section{Cardiac Response to $\boldsymbol{\beta}$-Adrenergic Stimulation}

We investigated the effects of $\mathrm{CO}$ exposure on the $\beta$-adrenergic reserve. In vivo, an acute $\beta$-adrenergic stimulation (using isoproterenol $1 \mathrm{mg} / \mathrm{kg}$ ) modified both the maximal rate of increase of LV pressure and the relaxation time constant tau in CO-treated and control rats. However, these effects were less pronounced in the $\mathrm{CO}$ group (Figure 6A). Isoproterenol increased the maximal and minimal first derivative of LV pressure by $65.4 \pm 9.1 \%$ in controls, but only by $27.9 \pm 9.7 \%$ in CO-exposed rats. Similarly, tau decreased by $15.1 \pm 3.3 \%$ in controls, but only by $3.7 \pm 3.9 \%$ in CO-exposed rats, highlighting a reduction in the lusitropic effect of isoproterenol after chronic $\mathrm{CO}$ exposure.

At the cardiomyocyte level, $\beta$-adrenergic stimulation activates PKA, which phosphorylates both $\mathrm{Ca}^{2+}$-handling proteins involved in ECC (RyR, PLB) and myofilament regulatory proteins (cTnI and MyBP-C). In our study, the positive inotropic effect of isoproterenol $(100 \mathrm{nM})$ on cell shortening was smaller in myocytes from CO-exposed animals than from controls. However, the potentiating effect of isoproterenol on $\mathrm{Ca}^{2+}$ transient amplitude was similar in control and CO myocytes (Figure 6B), suggesting that an alteration in the myofilament response is responsible for the decrease in contraction. Permeabilized myocytes were therefore incubated with a recombinant catalytic subunit of PKA (Figure 6C). PKA led to classic myofilament $\mathrm{Ca}^{2+}$ desensitization (decrease in $\mathrm{pCa}_{50}$ ). However this effect was 
A
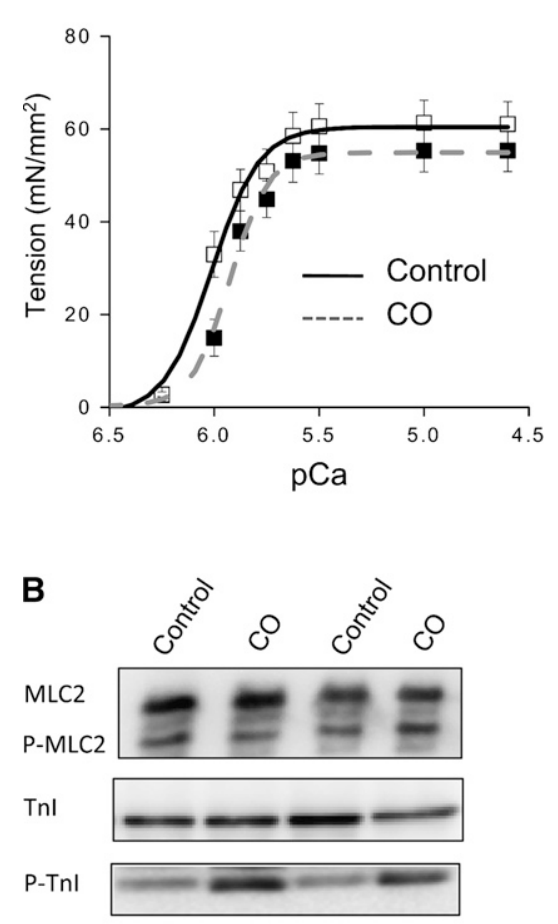
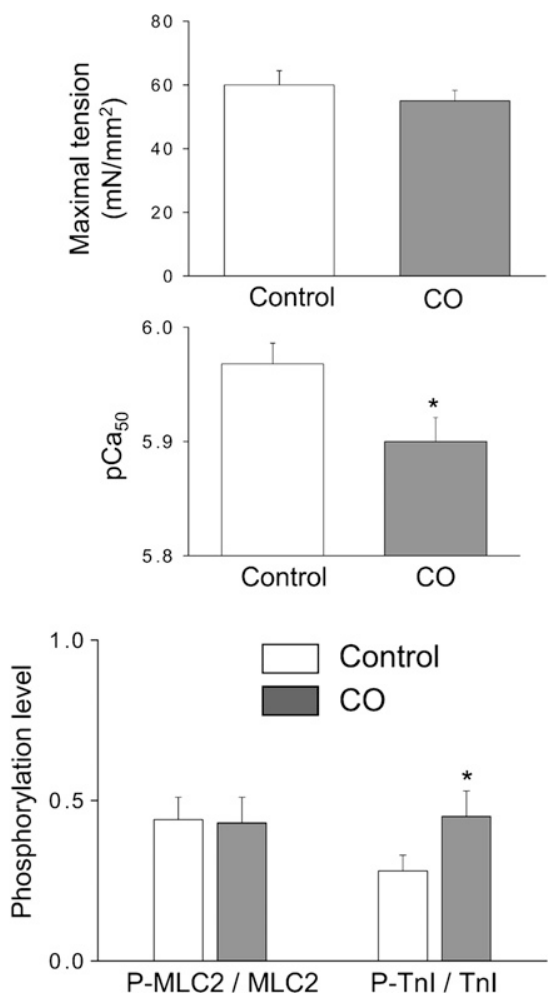

Figure 5. Effects of carbon monoxide (CO) pollution on contractile machinery in permeabilized cardiomyocytes. (A) The relationship between $\mathrm{Ca}^{2+}$-activated tension and intracellular $\mathrm{Ca}^{2+}$ content was measured at $2.3 \mu \mathrm{m}$ sarcomere length in permeabilized cardiomyocytes isolated from control and CO-exposed rats. The relationship was fitted with a modified Hill equation. The $\mathrm{pCa}$ at which half the maximal tension is developed $\left(\mathrm{pCa}_{50}\right.$, where $\left.\mathrm{pCa}=-\log _{10}\left[\mathrm{Ca}^{2+}\right]\right)$ was determined as an index of myofilament $\mathrm{Ca}^{2+}$ sensitivity ( $n=25-28$ cells $/ 5$ hearts). (B) Effect of chronic exposure to $\mathrm{CO}$ on the phosphorylation level of MLC-2 and CTnl in permeabilized cardiac strips from control and CO-exposed rats. Phosphorylation levels were determined by Western blotting with antibodies to P-MLC2 and to CTnl phosphorylated at the protein kinase A sites $\mathrm{Ser}^{22} / \mathrm{Ser}^{23}$ (P-CTnl), as described in Methods. ${ }^{*} P<0.05$ more pronounced in controls than in CO-exposed myocytes, such that the difference in myofilament $\mathrm{Ca}^{2+}$ sensitivity disappeared between control and $\mathrm{CO}$ myocytes after PKA treatment. Taken together, these data indicate that the $\beta$-adrenergic response is altered in animals exposed to chronic $\mathrm{CO}$ pollution.

\section{Oxidative Status in CO- exposed Animals}

It is well documented that $\mathrm{CO}$ binding to cytochrome-c oxidase in the electron transport chain as well as $\mathrm{CO}$ interaction with nitric oxide synthase (24) lead to generation of reactive oxygen species (ROS) and nitrogen species $(25,26)$. We thus evaluated whether the $\mathrm{CO}$-associated cardiac remodeling could involve oxidative stress. Cardiac antioxidant and oxidant statuses are presented in Figure 7. Chronic CO exposure decreased antioxidant enzyme activities of superoxide dismutase, catalase, and glutathione peroxidase. This decrease of antioxidant defenses buffering ROS was associated with increased activity of thioredoxin reductase, confirming a $\mathrm{CO}$-induced oxidative stress (27).

\section{DISCUSSION}

It is well established that air pollution is associated with cardiovascular outcome and can cause premature death. However, the mechanisms underlying these effects are poorly understood. We found that exposure of healthy rats to $\mathrm{CO}$ for a period limited to 4 weeks, under conditions mimicking urban air pollution, promoted cardiac remodeling and increased arrhythmogenic events. Although only a weak alteration of myocardium function was observed in vivo, marked changes in $\mathrm{Ca}^{2+}$ handling and $\mathrm{Ca}^{2+}$ sensitivity of contractile proteins occurred. To our knowledge, our data provide the first evidence at the cardiomyocyte level that chronic $\mathrm{CO}$ exposure promotes a pathological phenotype in the absence of underlying cardiopathy.

A key finding of the present study is that chronic $\mathrm{CO}$ exposure depresses the contraction of single rat ventricular myocytes because of reduction of both systolic $\mathrm{Ca}^{2+}$ release and myofilament $\mathrm{Ca}^{2+}$ sensitivity. In addition, the velocity of both the onset and the relaxation of contraction was markedly reduced, in agreement with a slowing of the $\mathrm{Ca}^{2+}$ transient decay. The reduced SERCA-2a expression induced by $\mathrm{CO}$ exposure is likely to account for the impairment in $\mathrm{Ca}^{2+}$ reuptake by the SR, and, therefore, for the delay in cell relaxation. The increase in PKA-phosphorylation of RyR-2 observed in CO-exposed animals is consistent with a $\mathrm{Ca}^{2+}$ leak in the $\mathrm{SR}$, known to contribute to intracellular $\mathrm{Ca}^{2+}$ overload and $\mathrm{SR} \mathrm{Ca}{ }^{2+}$ depletion $(22,28,29)$. A decrease in SERCA-2a expression could play a role not only in the reduction of $\mathrm{SR} \mathrm{Ca}^{2+}$ content but also, as a consequence, in the elevation of diastolic $\mathrm{Ca}^{2+}$.

Another major finding of this study is the proarrhythmogenic effect of chronic $\mathrm{CO}$ exposure in a healthy population. This result provides experimental support to previous reports that $\mathrm{CO}$ is associated with life- threatening VA in populations with cardiopathies $(30,31)$. The arrhythmic events may have an electrical origin or a $\mathrm{Ca}^{2+}$ origin (32). The lack of effect of $\mathrm{CO}$ on QT interval, the regionalized effect on AP duration, and the increase in diastolic $\mathrm{Ca}^{2+}$ concentration together support the hypothesis that the VAs observed after CO exposure are mediated by $\mathrm{Ca}^{2+}$ overload (33). The pathway proposed involves the $\mathrm{Ca}^{2+}$-dependent activation of $\mathrm{I}_{\mathrm{ti}}$ (the transient depolarizing inward $\mathrm{Na}^{+}$current), triggering delayed afterdepolarizations (34), with a facilitating role for $\beta$-adrenergic stimulation. Our demonstration of a PKA-dependent hyperphosphorylation of both RyR-2 and TnI is consistent with chronic $\beta$-adrenergic overstimulation during $\mathrm{CO}$ exposure, and contributes to its proarrhythmogenic effects.

The causative mechanisms involved in the chronic $\mathrm{CO}$ pollution-induced pathological cardiac phenotype could have a vascular origin, with limited blood delivery to the cardiac pump (35). Indeed, we demonstrated that, although coronary density was not modified after 4 weeks of $\mathrm{CO}$ exposure, perfusion was reduced during a cardiac stress (data not shown). A decreased oxygen delivery due to functional impairment, associated with probable repeated ischemia/reperfusion cycles induced by alternation of $\mathrm{CO}$ and ambient air exposure, is very 
A
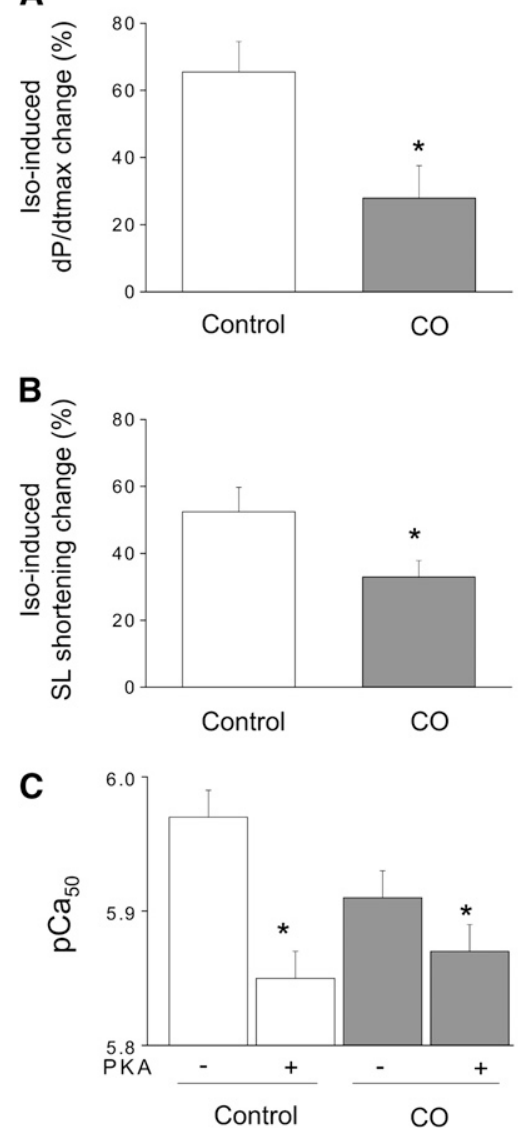
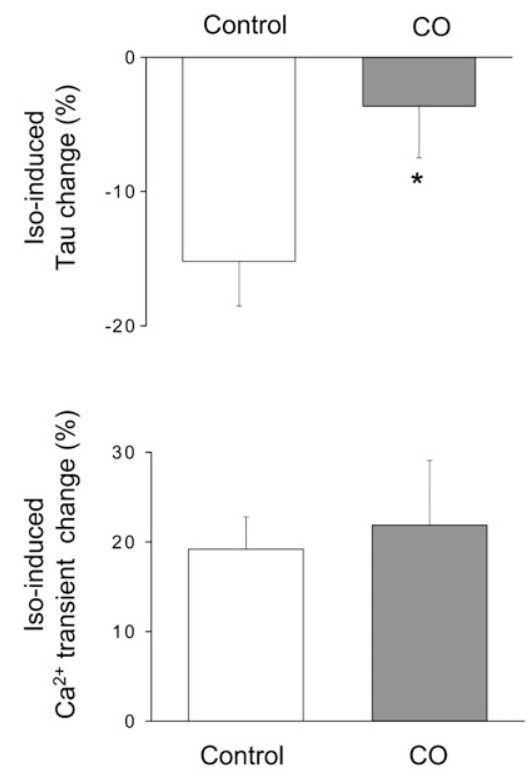

Figure 6. Effect of carbon monoxide (CO) pollution on the $\beta$-adrenergic reserve in vivo and in vitro. $(A)$ Variation of the maximal first derivative $(\mathrm{dP} / \mathrm{dt} \max )$ and relaxation time constant (tau) of left ventricular (LV) pressure after isoproterenol injection ( $1 \mathrm{mg} / \mathrm{kg}$; iso-induced) evaluated in vivo in control and CO-exposed animals $(\mathrm{n}=9$ rats in each group). (B) Variation of contraction (sarcomere length [SL] shortening) and $\mathrm{Ca}^{2+}$ transients in isolated LV cells in presence of $100 \mathrm{nM}$ isoproterenol (iso-induced) $(n=22$ cells for control rats and 37 cells for CO-exposed rats). (C) Myofilament $\mathrm{Ca}^{2+}$ sensitivity was similar between control and CO-exposed permeabilized cells after protein kinase $A(P K A)$ treatment $(100 \mathrm{U} / \mathrm{ml}$, incubation for $60 \mathrm{~min})(\mathrm{n}=21-27$ cells $/ 4$ hearts $)$. ${ }^{*} P<0.05$.

likely to induce recurrent stresses and initiate the pathological cardiac remodeling demonstrated in the $\mathrm{CO}$ group. Moreover, vascular alterations could enhance the well-established COassociated production of ROS and nitrogen species $(25,26)$. Indeed, $\mathrm{CO}$ binds to cytochrome-c oxidase of the electron transport chain and interacts with nitric oxide synthase, leading to peroxynitrite generation (24). Previous studies have shown that low-level CO exposure, as for urban pollution, causes oxidative stress (24). In accordance with these studies, we observed a marked increase in thioredoxin reductase activity in the CO-exposed rats associated with decreased antioxidant enzyme activities, suggesting increased oxidative stress. As proteins involved in $\mathrm{Ca}^{2+}$ handling are potential targets for redox modifications $(36,37)$, the cellular impairments observed in this study could be attributed partially to CO-induced ROS production. We show that chronic $\mathrm{CO}$ exposure increases PKAdependent phosphorylation of both RyR-2 and TnI. ROS may be responsible for the PKA-dependent phosphorylation of cardiac proteins because it has been shown that ROS can activate the PKA pathway $(38,39)$.
A

A
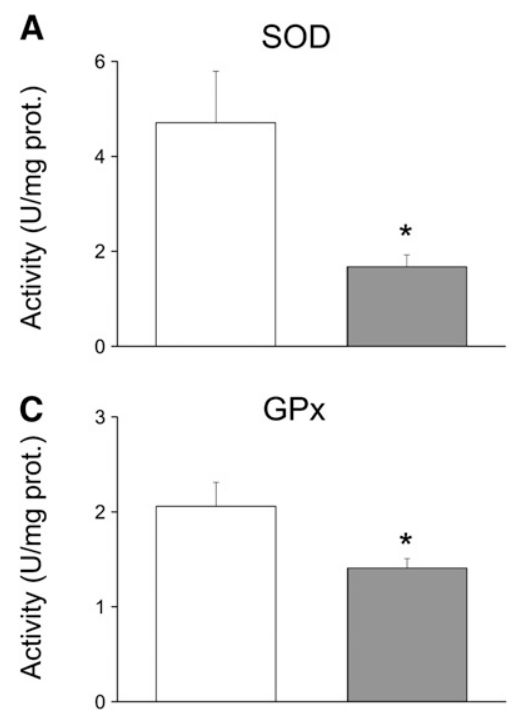

B

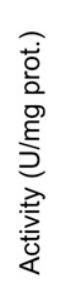

D
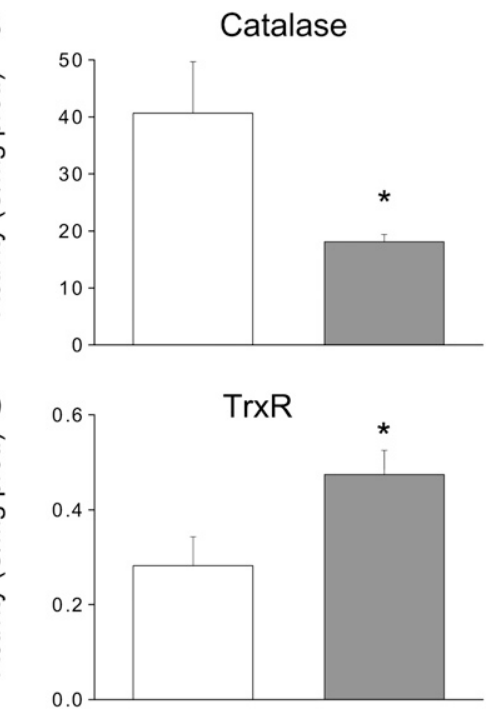

Figure 7. Cardiac oxidative status after chronic carbon monoxide (CO) exposure. Antioxidant activities of $(A)$ superoxide dismutase, $(B)$ catalase, and $(C)$ glutathione peroxidase evaluated in whole heart of control and COexposed animals ( $n=7$ rats in each group). (D) Thioredoxin reductase activities, an index of oxidative stress, measured in control and CO-exposed animals $(n=7$ rats in each group). ${ }^{*} P<0.05$. 
The toxic effect of high concentrations of $\mathrm{CO}$ is recognized. However, there is increasing evidence that a low concentration of $\mathrm{CO}$ is beneficial in diverse diseases in rodents, large animals, and humans (40). Low CO-dose gas inhalation but also synthetic CO-releasing molecules (CORM) have been recently used as potential therapeutic agents, particularly for cardiovascular diseases (41). CORM reduces infarct size (42), has a protective effect against myocardial infarction (42), prolongs survival of transplanted hearts, increases resistance to hypoxia-reoxygenation $(43,44)$, and improves cardiac mitochondrial metabolism (45). However, the beneficial cardiac effects of CORM were seen after acute perfusion, which differs from the chronic animal exposure model in the present study. The cardioprotective effects of low $\mathrm{CO}$ may be due to inhibition of L-type $\mathrm{Ca}^{2+}$ currents (46) occurring via redox modulation of key cysteine residues by mitochondrial ROS (47). In cardiac myocytes, rapid changes in cellular oxygen and ROS generation can contribute to electrophysiological instability and occurrence of arrhythmias via increased L-type $\mathrm{Ca}^{2+}$ current (see Reference 48 for review). Although moderate and variable across the $\mathrm{LV}$ wall, the increase in L-type $\mathrm{Ca}^{2+}$ current reported here might be consistent with an increased oxidative stress. At the moment, CO-based therapeutic strategies use short-term exposure. However, the potential toxicological effect of nontoxic doses of $\mathrm{CO}$ (30 ppm/d on average) on cardiac function should be relevant for future investigations of chronic treatment with low-dose $\mathrm{CO}$ gas inhalation or CORM.

\section{Study Limitations}

The cardiac effects of $\mathrm{CO}$ may result from a direct action on the heart and/or from indirect consequences of alterations in the respiratory system function. In fact, the level of carboxyhemoglobin measured 24 hours after the last $\mathrm{CO}$ exposure was not different from that of control rats, and was consistent with levels reached in human populations exposed to high atmospheric pollution $(12,13)$. These levels of carboxyhemoglobin are not reported to be associated, in the literature and in medical practice, with direct hypoxic stress. The pulmonary effects of $\mathrm{CO}$ remain controversial and are usually reported after chronic exposure to toxic doses, associated or not with other toxic agents $(49,50)$. In a set of preliminary experiments, we demonstrated that the mass of the right ventricle was not different between control and CO-exposed rats $(0.276 \pm 0.015$ vs. $0.286 \pm 0.015 \mathrm{~g}$, $\mathrm{n}=7$ in each group; $P=0.64)$, whereas that of the $\mathrm{LV}$ was significantly increased $(P=0.007)$ after chronic $\mathrm{CO}$ exposure $(1.02 \pm 0.01$ vs. $1.11 \pm 0.01 \mathrm{~g}$, in control and CO-exposed rats, respectively). Altogether, these data do not support a role for the respiratory system in the cardiac effects of $\mathrm{CO}$ reported here.

\section{Clinical Relevance}

Chronic $\mathrm{CO}$ exposure induced signs of cardiac stress and remodeling with several features commonly observed in pathology, such as HF, wherein impairment of myocardial pump function elicits chronic sympathetic nervous system activity to maintain cardiac output and blood pressure (16). Adrenergic hyperactivation promotes hypertrophy, increases heart rate, favors the development of interstitial fibrosis, and increases the risk of sudden cardiac death (51). Although chronic CO exposure induced only modest alterations in cardiac function in vivo, several abnormalities commonly observed in HF were detected. At the integrated level, they included a reduction in fractional shortening and end-systolic strain, parietal hypertrophy of the LV, an increase in fibrosis, an increase in basal heart rate, and a decrease in heart rate variability. At the cellular level, despite the absence of cellular hypertrophy and change in repolarizing $\mathrm{I}_{\text {to }}$ density, cardiomyocytes in $\mathrm{CO}$-exposed rats exhibited features typical of $\mathrm{HF}$, including elevated diastolic $\mathrm{Ca}^{2+}(22)$, reduced SR $\mathrm{Ca}^{2+}$ load (52), decreased systolic $\mathrm{Ca}^{2+}$ release (53), a lengthening of $\mathrm{Ca}^{2+}$ reuptake (54), and diminished $\mathrm{Ca}^{2+}$ sensitivity of the myofilaments $(15,18,55)$. In addition, the positive inotropic effect of isoproterenol was partially lost in vivo and in vitro, consistent with a decrease in the phosphorylation reserve, possibly because of an elevation of the adrenergic (hyperadrenergic) state to compensate for the altered contraction of cardiomyocytes. However, even if the pathological cellular function seems to be rescued in vivo under basal conditions, CO-exposed rats exhibited an enhanced arrhythmogenic potential on $\beta$-adrenergic stimulation, suggesting an increased risk for cardiac events under conditions of exercise and stress. Interestingly, because ROS are involved in the deleterious effects of $\mathrm{CO}$ pollution, antioxidant therapy provided by pharmacology, nutrition, or physical exercise could prevent the alterations reported here.

In conclusion, chronic exposure to $\mathrm{CO}$ levels consistent with environmental air pollution promotes moderate cardiac dysfunction in vivo in healthy rats. However, serious alterations occur at the cardiomyocyte level, potentially reflecting an early stage of cardiac pathology. Our findings provide a rationale at the cellular and molecular levels in support of earlier epidemiologic studies pointing to the deleterious effects of $\mathrm{CO}$ pollution on cardiac function. Further studies will aim at investigating whether the pathologic cellular phenotype evidenced in our study could exacerbate the effects of an acute stress, such as ischemia reperfusion or acute oxidative stress.

Conflict of Interest Statement: None of the authors has a financial relationship with a commercial entity that has an interest in the subject of this manuscript.

\section{References}

1. Miller KA, Siscovick DS, Sheppard L, Shepherd K, Sullivan JH, Anderson GL, Kaufman JD. Long-term exposure to air pollution and incidence of cardiovascular events in women. N Engl J Med 2007; 356:447-458.

2. Brook RD, Franklin B, Cascio W, Hong Y, Howard G, Lipsett M, Luepker R, Mittleman M, Samet J, Smith SC Jr, et al. Air pollution and cardiovascular disease: a statement for healthcare professionals from the Expert Panel on Population and Prevention Science of the American Heart Association. Circulation 2004;109: 2655-2671.

3. Finkelstein MM. Pollution-related mortality and educational level. JAMA 2002;288:830; author reply 830 .

4. Pope CA III, Burnett RT, Thun MJ, Calle EE, Krewski D, Ito K, Thurston GD. Lung cancer, cardiopulmonary mortality, and longterm exposure to fine particulate air pollution. JAMA 2002;287:11321141.

5. Henry CR, Satran D, Lindgren B, Adkinson C, Nicholson CI, Henry TD. Myocardial injury and long-term mortality following moderate to severe carbon monoxide poisoning. JAMA 2006;295:398-402.

6. Samoli E, Touloumi G, Schwartz J, Anderson HR, Schindler C, Forsberg B, Vigotti MA, Vonk J, Kosnik M, Skorkovsky J, et al. Short-term effects of carbon monoxide on mortality: an analysis within the APHEA project. Environ Health Perspect 2007;115:1578-1583.

7. Peters A, Doring A, Wichmann HE, Koenig W. Increased plasma viscosity during an air pollution episode: a link to mortality? Lancet 1997;349:1582-1587.

8. Dales R. Ambient carbon monoxide may influence heart rate variability in subjects with coronary artery disease. J Occup Environ Med 2004; 46:1217-1221.

9. Simkhovich BZ, Kleinman MT, Kloner RA. Air pollution and cardiovascular injury epidemiology, toxicology, and mechanisms. J Am Coll Cardiol 2008;52:719-726.

10. Stern FB, Halperin WE, Hornung RW, Ringenburg VL, McCammon CS. Heart disease mortality among bridge and tunnel officers exposed to carbon monoxide. Am J Epidemiol 1988;128:1276-1288. 
11. Wright GR, Jewczyk S, Onrot J, Tomlinson P, Shephard RJ. Carbon monoxide in the urban atmosphere: hazards to the pedestrian and the street-worker. Arch Environ Health 1975;30:123-129.

12. Joumard R, Chiron M, Vidon R, Maurin M, Rouzioux JM. Mathematical models of the uptake of carbon monoxide on hemoglobin at low carbon monoxide levels. Environ Health Perspect 1981;41:277-289.

13. Cole PV. Comparative effects of atmospheric pollution and cigarette smoking on carboxyhaemoglobin levels in man. Nature 1975;255:699-701.

14. Reboul C, Tanguy S, Juan JM, Dauzat M, Obert P. Cardiac remodeling and functional adaptations consecutive to altitude training in rats: implications for sea level aerobic performance. J Appl Physiol 2005;98:83-92.

15. Mou YA, Reboul C, Andre L, Lacampagne A, Cazorla O. Late exercise training improves non-uniformity of transmural myocardial function in rats with ischaemic heart failure. Cardiovasc Res 2009;81:555-564.

16. Fauconnier J, Bedut S, Le Guennec JY, Babuty D, Richard S. Ca2+ current-mediated regulation of action potential by pacing rate in rat ventricular myocytes. Cardiovasc Res 2003;57:670-680.

17. Stoll M, Quentin M, Molojavyi A, Thamer V, Decking UK. Spatial heterogeneity of myocardial perfusion predicts local potassium channel expression and action potential duration. Cardiovasc Res 2008;77:489-496.

18. Cazorla O, Szilagyi S, Le Guennec JY, Vassort G, Lacampagne A. Transmural stretch-dependent regulation of contractile properties in rat heart and its alteration after myocardial infarction. FASEB J 2005;19:88-90

19. Cazorla O, Szilagyi S, Vignier N, Salazar G, Kramer E, Vassort G, Carrier L, Lacampagne A. Length and protein kinase A modulations of myocytes in cardiac myosin binding protein C-deficient mice. Cardiovasc Res 2006;69:370-380.

20. Boucher F, Tanguy S, Besse S, Tresallet N, Favier A, de Leiris J. Agedependent changes in myocardial susceptibility to zero flow ischemia and reperfusion in isolated perfused rat hearts: relation to antioxidant status. Mech Ageing Dev 1998;103:301-316.

21. Cheng H, Lederer WJ. Calcium sparks. Physiol Rev 2008;88:1491-1545.

22. Marx SO, Reiken S, Hisamatsu Y, Jayaraman T, Burkhoff D, Rosemblit N, Marks AR. PKA phosphorylation dissociates FKBP12.6 from the calcium release channel (ryanodine receptor): defective regulation in failing hearts. Cell 2000;101:365-376.

23. Solaro RJ. Multiplex kinase signaling modifies cardiac function at the level of sarcomeric proteins. J Biol Chem 2008;283:26829-26833.

24. Thom SR, Fisher D, Xu YA, Notarfrancesco K, Ischiropoulos H. Adaptive responses and apoptosis in endothelial cells exposed to carbon monoxide. Proc Natl Acad Sci USA 2000;97:1305-1310.

25. Piantadosi CA. Carbon monoxide poisoning. N Engl J Med 2002;347: 1054-1055.

26. Piantadosi CA. Biological chemistry of carbon monoxide. Antioxid Redox Signal 2002;4:259-270.

27. Zhang J, Piantadosi CA. Mitochondrial oxidative stress after carbon monoxide hypoxia in the rat brain. J Clin Invest 1992;90:1193-1199.

28. Yano M, Ikeda Y, Matsuzaki M. Altered intracellular Ca2+ handling in heart failure. J Clin Invest 2005;115:556-564.

29. Bers DM, Eisner DA, Valdivia HH. Sarcoplasmic reticulum Ca2+ and heart failure: roles of diastolic leak and $\mathrm{Ca} 2+$ transport. Circ Res 2003;93:487-490.

30. Wellenius GA, Coull BA, Batalha JR, Diaz EA, Lawrence J, Godleski JJ. Effects of ambient particles and carbon monoxide on supraventricular arrhythmias in a rat model of myocardial infarction. Inhal Toxicol 2006;18:1077-1082.

31. Peters A, Liu E, Verrier RL, Schwartz J, Gold DR, Mittleman M, Baliff $\mathrm{J}$, Oh JA, Allen G, Monahan K, et al. Air pollution and incidence of cardiac arrhythmia. Epidemiology 2000;11:11-17.

32. Pasquie JL, Richard S. Prolongation in QT interval is not predictive of $\mathrm{Ca} 2+$-dependent arrhythmias: implications for drug safety. Expert Opin Drug Saf 2009;8:57-72.

33. Ter Keurs HE, Boyden PA. Calcium and arrhythmogenesis. Physiol Rev 2007;87:457-506.

34. Janse MJ. Electrophysiological changes in heart failure and their relationship to arrhythmogenesis. Cardiovasc Res 2004;61:208-217.

35. Favory R, Lancel S, Tissier S, Mathieu D, Decoster B, Neviere R. Myocardial dysfunction and potential cardiac hypoxia in rats induced by carbon monoxide inhalation. Am J Respir Crit Care Med 2006;174: 320-325.

36. Zima AV, Blatter LA. Redox regulation of cardiac calcium channels and transporters. Cardiovasc Res 2006;71:310-321.

37. Zissimopoulos S, Docrat N, Lai FA. Redox sensitivity of the ryanodine receptor interaction with FK506-binding protein. J Biol Chem 2007; 282:6976-6983.

38. Brennan JP, Bardswell SC, Burgoyne JR, Fuller W, Schroder E, Wait R, Begum S, Kentish JC, Eaton P. Oxidant-induced activation of type I protein kinase A is mediated by RI subunit interprotein disulfide bond formation. J Biol Chem 2006;281:21827-21836.

39. de Lamirande E, O'Flaherty C. Sperm activation: role of reactive oxygen species and kinases. Biochim Biophys Acta 2008;1784:106-115.

40. Otterbein LE. The evolution of carbon monoxide into medicine. Respir Care 2009;54:925-932.

41. Foresti R, Bani-Hani MG, Motterlini R. Use of carbon monoxide as a therapeutic agent: promises and challenges. Intensive Care Med 2008;34:649-658.

42. Guo Y, Stein AB, Wu WJ, Tan W, Zhu X, Li QH, Dawn B, Motterlini $\mathrm{R}$, Bolli R. Administration of a CO-releasing molecule at the time of reperfusion reduces infarct size in vivo. Am J Physiol Heart Circ Physiol 2004;286:H1649-H1653.

43. Clark JE, Naughton P, Shurey S, Green CJ, Johnson TR, Mann BE, Foresti R, Motterlini R. Cardioprotective actions by a water-soluble carbon monoxide-releasing molecule. Circ Res 2003;93:e2-e8.

44. Varadi J, Lekli I, Juhasz B, Bacskay I, Szabo G, Gesztelyi R, Szendrei L, Varga E, Bak I, Foresti R, et al. Beneficial effects of carbon monoxide-releasing molecules on post-ischemic myocardial recovery. Life Sci 2007;80:1619-1626.

45. Lancel S, Hassoun SM, Favory R, Decoster B, Motterlini R, Neviere R. Carbon monoxide rescues mice from lethal sepsis by supporting mitochondrial energetic metabolism and activating mitochondrial biogenesis. J Pharmacol Exp Ther 2009;329:641-648.

46. Uemura K, Adachi-Akahane S, Shintani-Ishida K, Yoshida K. Carbon monoxide protects cardiomyogenic cells against ischemic death through L-type $\mathrm{Ca} 2+$ channel inhibition. Biochem Biophys Res Commun 2005;334:661-668.

47. Scragg JL, Dallas ML, Wilkinson JA, Varadi G, Peers C. Carbon monoxide inhibits $\mathrm{L}$-type $\mathrm{Ca} 2+$ channels via redox modulation of key cysteine residues by mitochondrial reactive oxygen species. J Biol Chem 2008;283:24412-24419.

48. Hool LC. Acute hypoxia differentially regulates $\mathrm{K}(+)$ channels. Implications with respect to cardiac arrhythmia. Eur Biophys J 2005;34:369-376.

49. Zheng H, Liu Y, Huang T, Fang Z, Li G, He S. Development and characterization of a rat model of chronic obstructive pulmonary disease (COPD) induced by sidestream cigarette smoke. Toxicol Lett 2009; $189: 225-234$

50. Ghosh S, Wilson MR, Choudhury S, Yamamoto H, Goddard ME, Falusi B, Marczin N, Takata M. Effects of inhaled carbon monoxide on acute lung injury in mice. Am J Physiol Lung Cell Mol Physiol 2005; 288:L1003-L1009.

51. Maass AH, Ikeda K, Oberdorf-Maass S, Maier SK, Leinwand LA. Hypertrophy, fibrosis, and sudden cardiac death in response to pathological stimuli in mice with mutations in cardiac troponin $\mathrm{T}$. Circulation 2004;110:2102-2109.

52. Hobai IA, O'Rourke B. Decreased sarcoplasmic reticulum calcium content is responsible for defective excitation-contraction coupling in canine heart failure. Circulation 2001:103:1577-1584.

53. Gomez AM, Valdivia HH, Cheng H, Lederer MR, Santana LF, Cannell MB, McCune SA, Altschuld RA, Lederer WJ. Defective excitationcontraction coupling in experimental cardiac hypertrophy and heart failure. Science 1997;276:800-806.

54. Piacentino V III, Weber CR, Chen X, Weisser-Thomas J, Margulies KB, Bers DM, Houser SR. Cellular basis of abnormal calcium transients of failing human ventricular myocytes. Circ Res 2003;92:651-658.

55. Perez NG, Hashimoto K, McCune S, Altschuld RA, Marban E. Origin of contractile dysfunction in heart failure: calcium cycling versus myofilaments. Circulation 1999;99:1077-1083. 